\title{
Genome-wide array comparative genomic hybridization analysis reveals distinct amplifications in osteosarcoma
}

\author{
Tsz-Kwong Man ${ }^{\dagger 1}$, Xin-Yan Lu ${ }^{\dagger 1}$, Kim Jaeweon ${ }^{2}$, Laszlo Perlaky ${ }^{1}$, \\ Charles P Harris ${ }^{1}$, Shishir Shah ${ }^{2}$, Marc Ladanyi $^{3}$, Richard Gorlick ${ }^{4}$, \\ Ching C Lau ${ }^{1}$ and Pulivarthi H Rao*1
}

\begin{abstract}
Address: ${ }^{1}$ Texas Children's Cancer Center, Baylor College of Medicine, Houston, TX, USA, ${ }^{2}$ Spectral Genomics, Houston, TX, USA, ${ }^{3}$ Department of Pathology, Memorial Sloan Kettering Cancer Center, New York, New York, USA and ${ }^{4}$ Department of Pediatrics, Memorial Sloan Kettering Cancer Center, New York, New York, USA

Email: Tsz-Kwong Man - tcman@txccc.org; Xin-Yan Lu - xxlu@txccc.org; Kim Jaeweon - jkim@spectralgenomics.com; Laszlo Perlaky - lxperlak@txccc.org; Charles P Harris - cpharris@txccc.org; Shishir Shah - shishir@houston.rr.com; Marc Ladanyi - ladanyim@mskcc.org; Richard Gorlick - gorlickr@mskcc.org; Ching C Lau - cclau@txccc.org; Pulivarthi H Rao* - phrao@txccc.org

* Corresponding author †Equal contributors
\end{abstract}

Published: 07 August 2004

BMC Cancer 2004, 4:45 doi:10.1 I86/I47|-2407-4-45
Received: 04 May 2004

Accepted: 07 August 2004

This article is available from: http://www.biomedcentral.com/147/-2407/4/45

(c) 2004 Man et al; licensee BioMed Central Ltd.

This is an open-access article distributed under the terms of the Creative Commons Attribution License (http://creativecommons.org/licenses/by/2.0), which permits unrestricted use, distribution, and reproduction in any medium, provided the original work is properly cited.

\begin{abstract}
Background: Osteosarcoma is a highly malignant bone neoplasm of children and young adults. It is characterized by extremely complex karyotypes and high frequency of chromosomal amplifications. Currently, only the histological response (degree of necrosis) to therapy represent gold standard for predicting the outcome in a patient with non-metastatic osteosarcoma at the time of definitive surgery. Patients with lower degree of necrosis have a higher risk of relapse and poor outcome even after chemotherapy and complete resection of the primary tumor. Therefore, a better understanding of the underlying molecular genetic events leading to tumor initiation and progression could result in the identification of potential diagnostic and therapeutic targets.

Methods: We used a genome-wide screening method - array based comparative genomic hybridization (arrayCGH) to identify DNA copy number changes in 48 patients with osteosarcoma. We applied fluorescence in situ hybridization (FISH) to validate some of amplified clones in this study.

Results: Clones showing gains (79\%) were more frequent than losses (66\%). High-level amplifications and homozygous deletions constitute $28.6 \%$ and $3.8 \%$ of tumor genome respectively. High-level amplifications were present in 238 clones, of which about $37 \%$ of them showed recurrent amplification. Most frequently amplified clones were mapped to Ip36.32 (PRDM/6), 6p2I.I (CDC5L, HSPCB, NFKBIE), 8q24, I2qI4.3 (IFNG), I6pI3 (MGRNI), and I7pII.2 (PMP22 MYCD, SOXI,ELAC27). We validated some of the amplified clones by FISH from 6pI2-p21, 8q23-q24, and 17pII.2 amplicons. Homozygous deletions were noted for 32 clones and only 7 clones showed in more than one case. These 7 clones were mapped to Iq25.I (4 cases), 3pI4.I (4 cases), I3qI2.2 (2 cases), 4 pI5.I ( 2 cases), 6qI2 (2 cases), 6qI2 (2 cases) and 6qI6.3 (2 cases).

Conclusions: This study clearly demonstrates the utility of array CGH in defining high-resolution DNA copy number changes and refining amplifications. The resolution of array CGH technology combined with human genome database suggested the possible target genes present in the gained or lost clones.
\end{abstract}




\section{Background}

Osteosarcoma (OS) is a primary malignant tumor of bone arising from primitive bone-forming mesenchymal cells and it accounts for approximately $60 \%$ of malignant bone tumors in the first two decades of life [1]. These tumors typically arise in the metaphyseal regions of long bones, with the distal femur, proximal tibia and proximal humerus. A significant number of osteosarcomas are of conventional type which can be subdivided into three major categories based on their predominant differentiation of tumor cells: osteoblastic, chondroblastic, and fibroblastic. Currently, only the histological response (degree of necrosis) to therapy represent gold standard for predicting the outcome in a patient with non-metastatic osteosarcoma at the time of definitive surgery [2]. Patients with lower degree of necrosis have a higher risk of relapse and poor outcome even after chemotherapy and complete resection of the primary tumor. Therefore, a better understanding of the underlying molecular genetic events leading to tumor initiation and progression could result in the identification of potential diagnostic and therapeutic targets.

Chromosomal aberrations in osteosarcoma are highly complex and characterized by high frequency of amplifications. These amplifications may result in the overexpression of genes and contribute to the genomic instability in osteosarcoma. The identification of genes within the amplified sites is crucial for understanding the biology and clinical behavior of osteosarcoma. Until, recently gene amplification has been detected by PCR, southern blot analysis or FISH-based approach using gene specific probes. These techniques are inherently restricted to the previously known amplified genes in the genome. In contrast, genome-wide screening of amplified chromosomal regions with $\mathrm{CGH}$ has become an important tool for the detection of amplified regions in the tumor genome. So far published chromosomal CGH studies in osteosarcoma have identified several high-level chromosomal amplifications at $1 \mathrm{p} 22,1 \mathrm{p} 31,1 \mathrm{q} 21,1 \mathrm{q} 23,2 \mathrm{q} 24,3 \mathrm{p} 25,3 \mathrm{q} 26$, 6q24.3, 4q12, 5p14-p15, 5q33, 6p12-p21, 6q24.3, 7p21p22, 8q12-q23, 10p21, 10q11.1, 10q22, 11q13, 11q23, 12p13, 12q12-q15, 17p11.2, 17q21, 18q22, 19p13.1 and 20p11.2 [3-7]. However, conventional CGH has limited sensitivity and resolution ( 10-15 megabases) because of its dependence on the morphology of metaphase chromosomes. In addition, extensive follow-up work is required to identify candidate genes after regions of gain or loss have been identified. Recently, novel method termed as array-based comparative genomic hybridization (array CGH) has been described, which enables high throughput quantitative measurement of high-resolution DNA copy number changes throughout the genome [8]. This method is based on hybridization of differentially labeled test and reference DNAs to an array of mapped human genomic DNA fragments ( 100-200 kb) and has been recently applied to human and mouse tumors [9-14]. To identify high-resolution copy number, we used array CGH to the panel of 48 tumors. The resolution of array CGH technology combined with human genome database not only allowed a precise identification of amplicons but also suggested the possible target genes within the amplicons.

\section{Methods \\ Patient samples}

A total of 48 tumors from 42 patients (20 males and 22 females) were collected from the Texas Children's Cancer Center, Houston, TX (tumors 193, 196, 204, 209, 221, 226, 248, 274, 295, 311, 326, 341, 345, 360, 400, 464, 481, 501, 527, 591 and 606) and Memorial Sloan Kettering Cancer Center, New York (tumors 06, 15, 24, 25, 27, 29, 32, 34, 40, 48, 68, 76, 78, 79, 80, 82, 83, 85, 88, 95, $98,99,102,123,423,425$, and 474). All tissues in this study were obtained after IRB approved informed consents were signed. The age at diagnosis ranged from 5 years to 71 years at diagnosis. The histological information of 42 patients is presented in Table 1.

\section{Array CGH}

The array used in this study consists of 967 human BACs, which were spaced approximately 3 megabase across the whole genome. These arrays were obtained from Spectral Genomics, Houston, TX. The experiments were performed according to the manufacturer's protocol. Arrays were prehybridized with human Cot-I DNA (GIBCO Invitrogen, Carlsbad, CA) and salmon testes DNA to block the repetitive sequences on BACs. One microgram of normal DNA (reference) and tumor DNA (test) was labeled with cy5dUTP and cy3-dUTP respectively, by random priming. To avoid dye bias, we performed dye swap experiments for each sample. The probe mixture is dissolved in hybridization mixture, denatured, cooled, and mounted with $22 \times$ $60 \mathrm{~mm}$ coverslip. Hybridizations were performed in sealed chambers for $16-20$ hours at $60^{\circ} \mathrm{C}$. After post hybridization washes, arrays were rinsed, dried with compressed air, and scanned into two 16-bit TIFF image files using Gene Pix 4000A two-color fluorescent scanner (Axon Instruments, Inc., Union City, CA) and quantitated using GenePix software (Axon Instruments, Union City, CA).

\section{Data processing and analysis}

After scanning of the slide, the fluorescent intensities of the green and red channels were background subtracted. The resulting values were normalized by intensity based local weighted regression method (Lowess) to correct for systematic bias in dye labeling and fluorescent intensity [15]. Then the ratio of the red/green channel of each clone was calculated and $\log$ base 2 transformed (log ratios). 
Table I: Histological information on $\mathbf{4 8}$ osteosarcoma samples

\begin{tabular}{|c|c|c|c|c|c|c|c|c|}
\hline $\begin{array}{l}\text { Tumor } \\
\text { No. }\end{array}$ & Sex & Age-Dx & Site & Histological Subtype & Type & $\begin{array}{l}\text { Metastatic } \\
\text { Disease }\end{array}$ & $\begin{array}{l}\text { Huvos } \\
\text { Grade }\end{array}$ & Response \\
\hline 06 & Female & 7 & Distal Femur & NA & Biopsy & L & II & PR \\
\hline 15 & Male & 35 & Distal Femur & Osteoblastic+MFH-Like & Biopsy & L & & \\
\hline 24 & Female & 16 & Clavicle & Chondroblastic & Biopsy & L & Minimal & \\
\hline 25 & Male & 8 & Skull & Osteoblastic & Mets & L & & \\
\hline 27 & Female & 34 & Ischium & $\begin{array}{l}\text { Mixed } \\
\text { Chondroblastic+Fibroblastic-Like }\end{array}$ & Mets & L & & \\
\hline 29 & Male & 19 & Ilium & NA & Biopsy & M & II & PR \\
\hline 32 & Female & 25 & Ilium & Chondroblastic & Biopsy & $\mathrm{L}$ & Minimal & \\
\hline 34 & 15 & Femur & $\begin{array}{l}\text { Chndroblastic And } \\
\text { Osteoblastic }\end{array}$ & Biopsy & $\mathrm{L}$ & II & PR & \\
\hline 40 & Female & 11 & Left Distal Femur & Giant Cell & Definitive & None & IV & GR \\
\hline 48 & Female & 32 & Proximal Tibia & Osteo/Fibro/Chondroblastic & Definitive & None & 1 & PR \\
\hline 68 & Male & 18 & Femur & Telangectactic & Mets & & & \\
\hline 76 & Female & 20 & Thigh & N/A & Biopsy & L & & \\
\hline 78 & Male & 5 & Humerus & N/A & Biopsy & L & III & GR \\
\hline 79 & Male & 9 & Tibia & Telangectactic & Mets & L & III & GR \\
\hline 80 & Male & 46 & Tibia & $\mathrm{N} / \mathrm{A}$ & Biopsy & L & I & PR \\
\hline 82 & Male & 23 & Humerus & Osteoblastic & Mets & L & I & PR \\
\hline 83 & Female & 12 & Femur & Telangiectatic & Biopsy & $\mathrm{L}$ & IV & GR \\
\hline 85 & Male & 34 & Femur & Fibroblastic & Biopsy & $\mathrm{L}$ & 1 & $P R$ \\
\hline 88 & Male & 17 & Humerus & Chndorblastic & Biopsy & L & IV & GR \\
\hline 95 & Male & 71 & Femur & Giant Cel Rich & Biopsy & L & & \\
\hline 98 & Female & 31 & Ilium & Epithelioid & Biopsy & L & & \\
\hline 99 & Female & 22 & Humerus & $\mathrm{N} / \mathrm{A}$ & Biopsy & L & & \\
\hline 102 & Male & 70 & Humerus & Fibrohistiocytic & Mets & L & & \\
\hline 123 & Female & 16 & Femur & N/A & Biopsy & $\mathrm{L}$ & I & PR \\
\hline 209 & Female & 17 & Distal Femur & Osteoblastic & Biopsy & No & II & PR \\
\hline 221 & Female & 17 & Femur & Osteoblastic & Biopsy & No & IV & GR \\
\hline 248 & Female & 13 & Tibia & Pleiomorphic & Biopsy & No & $?$ & \\
\hline 311 & Female & 13 & Distal Femur & Osteoblastic & Definitive & No & III & GR \\
\hline 326 & Female & 20 & Femur & Osteoblastic & Pul Met & Yes & IV & GR \\
\hline 341 & Male & 12 & Lemur & Fibroblastic & Biopsy & $N$ & II & $P R$ \\
\hline 345 & Male & 10 & Distal Femur & Osteosarcoma & Biopsy & No & IV & GR \\
\hline 360 & Female & 18 & Distal Femur & Osteoblastic & Biopsy & Yes & IV & GR \\
\hline 400 & Female & 15 & Distal Femur & Chondroblastic & Yes & & & \\
\hline 423 & Male & 30 & Proximal Humerus & Giant Cell & Definitive & None & 1 & PR \\
\hline 425 & Male & 24 & Tibia & $\mathrm{N} / \mathrm{A}$ & Biopsy & $\begin{array}{l}\text { Proximal } \\
\text { Femur }\end{array}$ & 1 & PR \\
\hline 474 & Female & 17 & Pelvis & Chondroblastic & Biopsy & None & II & PR \\
\hline 591 & Male & 15 & Proximal L Tibia & Telangectactic & Definitive & No & II & PR \\
\hline $193 a$ & Female & 17 & Distal Femur & Osteoblastic & Biopsy & No & & \\
\hline $196 a$ & Female & 15 & Distal Femur & Osteoblastic & Pul Met & Yes & & \\
\hline $274 b$ & Male & 13 & Distal Femur & Osteoblastic//Chondroblastic & Biopsy & No & II & PR \\
\hline $295 b$ & Male & 13 & Femur & Osteoblastic//Chondroblastic & Yes & II & PR & \\
\hline $464 c$ & Female & 15 & Distal Femoral Head & $\begin{array}{l}\text { Osteoblastic/Spindle Cell/ } \\
\text { Chondroblastic }\end{array}$ & Biopsy & No & II & PR \\
\hline $50 \mathrm{lc}$ & Female & 15 & Femur & Osteoblastic & Definitive & No & II & PR \\
\hline $606 c$ & Female & 14 & Distal Femur & Osteoblastic & Biopsy & Yes & II & PR \\
\hline $48 I d$ & Male & 10 & Distal Femur & Osteoblastic & Biopsy & No & II & PR \\
\hline $527 d$ & Male & 10 & Proximal Tibia & Osteoblastic & Definitive & Yes & III & GR \\
\hline $204 \mathrm{e}$ & Female & 18 & Distal Femur & Osteoblastic & Biopsy & No & 1 & PR \\
\hline $226 \mathrm{e}$ & Female & 18 & Distal Femur & Telangectactic & Definitive & No & I & PR \\
\hline
\end{tabular}

a, b, c, d, e-Tumor samples obtained from the same patient. 
Each experiment was repeated once with dye reversal to addressing the confounding effect of the dye and experiment. The average of the dye-reversal experiment pair was calculated by reversing the sign of one experiment so that the log ratio reflects the tumor versus normal ratio.

We developed a new analytical method called invariant analysis to define the significant copy number changes. This method is designed to: i) increase the power of the analysis by combining all the cases in our dataset to define an invariant population (unchanged population); and, ii) to address the signal to noise differences among individual cases due to sample and hybridization variability. Our goal is to define a set of unchanged clones that can be used to calculate the upper and lower bound thresholds of the log ratios for the unchanged population in each experiment. First, we calculated the variance of each clone from all the experiments. We computed the p-values of the each clone by comparing to the clone with median variance using chi-square distribution http://linus.nci.nih.gov/ nbrb/TechReport.htm. The clones that have p-value greater than preset cutoff 0.9 were considered as invariant clone set, i.e. clones that do not vary significantly in all experiments. Then the mean and standard deviation of the log ratios of these invariant clones in each experiment were calculated. The clones with log ratios that exceed mean $+/-2 \times$ SD of the invariant set were considered gains and losses, respectively. For amplification and homozygous deletions, clones were defined to have at least 2 fold of the upper bound threshold and 4-fold of lower bound threshold, respectively. The gene(s) present in the clones were identified using UCSC browser http:// genome.ucsc.edu/cgi-bin/hgGateway ?org=human by downloading gene table (refFlat) from human gene assembly, July 2003. We search the candidate genes based on linear mapping position, which include $100 \mathrm{~kb}$ up and downstream from the clone center position. The supplemental data for this article is available at: https://big file.bcm.tmc.edu/outbound/prao/supplemental\%20data\%20Man\%20et\%20al.xls

\section{Statistical analysis}

Significant clones in $6 \mathrm{p}, 8 \mathrm{q}, 12 \mathrm{q}$ and $17 \mathrm{p}$ amplicons were calculated using 2-sample t-test with randomized variance model http://linus.nci.nih.gov/ brb/TechReport.htm. The experiments in each of the two groups, amplification and normal, used for comparison were defined based on the invariant analysis (see above). The clones that have $p$ $<0.001$ were considered as significant. We chose a stringent cutoff to minimize the multiple testing problem.

\section{FISH}

FISH was performed to validate and quantify chromosomal amplicons using clones from 6p12-p21 (RP1191E11, AL391415, RP11-81F7, RP11-79I2, RP11-90H17

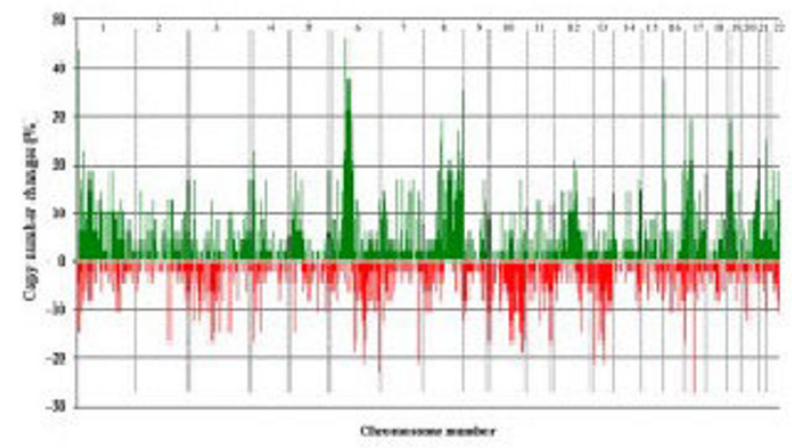

\section{Figure I}

Frequency of DNA copy number changes identified by array $\mathrm{CGH}$ in 48 osteosarcomas. The gains and losses are depicted as green and red color bars respectively. Clones are arranged from chromosome I to 22 and within each chromosome on the basis of UCSF mapping position.

and RP11-79F13), 8q24.3 (RP11-89K10), and 17p11.2p12 (RP11-64B12, RP11-89K6 and RP11-189D22 on tumors metaphase/interphase cells from cases 274, 364, $425,426,527$ and 628 . We confirmed the map positions of all clones on normal human metaphase cells by FISH. The bacterial artificial chromosome (BAC) clones, and centromeric clone from 6 (pEDZ6) were labeled with Spectrum Red or Spectrum Green (Vysis, Downers Grove, IL) by nick translation. Hybridization and FISH analysis was performed as described previously [16].

\section{Results}

To define the gains and losses in our experiments, we used invariant analysis for the first time to describe genomic changes by array CGH. In this method, we defined an invariant clone set that has low variance of log ratios among all the array experiments. After the mean and standard deviation of the log ratios in the invariant set of each experiment were calculated, clones that have higher or lower log ratios than the mean $+/-2$ SD of the invariant set (upper bound and lower bound) were used to define gains and losses. We chose to use this method because it addresses some of the shortcomings of the modeling method, such as using all information provided in a set of experiment to determine the unchanged population instead of using one experiment at a time. However, the variation of each experiment is accounted for because the thresholds are calculated using the invariant set from each experiment. It also does not require a separate reference set for comparison. Finally, it provides an adjustable cut- 
Table 2: Most frequently lost clones.

\begin{tabular}{|c|c|c|c|c|}
\hline Clone & Map Position (Mb) & Cyto Position & Frequency (\%) & Genes \\
\hline RPII-79KI5 & 31.9 & $17 q 12$ & 27 & \\
\hline RPI-I40CI2 & 170.4 & $6 q 27$ & 22.9 & PSMBI \\
\hline RPII-90MI5 & 24.8 & $13 q \mid 2.2$ & 20.8 & \\
\hline RPII-79|4 & 73.4 & $13 q 22.1$ & 20.8 & $K L F I 2$ \\
\hline RPII-79K22 & 101.7 & $6 q 16.3$ & 20.8 & MTMR6, NUPLI \\
\hline AC004889 & $|48.40|$ & $7 q 35$ & 20.8 & OR2A4 \\
\hline RPII-89H7 & 116.5 & $10 q 25.3$ & 18.8 & \\
\hline AL359836 & 128.22 & 10q26.11 & 18.8 & \\
\hline RPII-80LI6 & 67 & $6 q 12$ & 18.8 & \\
\hline RPII-80DI0 & 2.8 & 10p|5.1 & 16.7 & \\
\hline AC021027 & 84.029 & $10 q 22.3$ & 16.7 & \\
\hline RPII-79E24 & 88 & 10q23.2 & 16.7 & \\
\hline RPII-90BI9 & 131.5 & $10 q 26.3$ & 16.7 & \\
\hline RPII-835G2 I & 143.17 & $1 \mathrm{lq25}$ & 16.7 & \\
\hline $\mathrm{RPI}-80 \mathrm{H} 2$ & 50 & $13 q \mid 4.3$ & 16.7 & \\
\hline RPII-8ID9 & 72.8 & $13 q 22.1$ & 16.7 & \\
\hline RP5-I029F2I & 1.21 & $|7 p| 3.3$ & 16.7 & \\
\hline AC02068I & 175.95 & $2 q 31.1$ & 16.7 & PDKI \\
\hline RPII-89AI2 & 68 & $3 p \mid 4.1$ & 16.7 & \\
\hline RPII-9AI & 71.28 & $3 p \mid 4.1$ & 16.7 & \\
\hline RPII-492123 & 3.64 & $4 p 16.2$ & 16.7 & \\
\hline RPI-46BI & 69.4 & $6 q 12$ & 16.7 & $B A 13$ \\
\hline RP3-454N4 & 106 & $6 q 21$ & 16.7 & \\
\hline
\end{tabular}

off to optimize the thresholds to the training data, if provided.

The amplified and homozygously deleted clones were defined to have at least 2 fold of the upper bound and 4fold of lower bound, respectively. Figure 1 summarizes the high-resolution DNA copy number changes identified by array CGH in 48 osteosarcomas derived from 42 patients. Copy number changes were detected involving small genomic regions, whole chromosomes, and chromosomal arms showing homozygous deletions and highlevel amplifications.

\section{Overview of genomic profiles}

Copy number changes excluding clones from sex chromosomes were involved in a significant fraction of most tumor genome. The estimated average genomic distance between clones was 3-4 Mb. The frequency of clones showing gains $(79 \%)$ was greater than losses (66\%). High-level amplifications and homozygous deletions constitute $28.6 \%$ and $3.8 \%$ of tumor genome respectively. The most frequently deleted clones were identified from the chromosomal regions $2 \mathrm{q} 31.1,3 \mathrm{p} 14.1,4 \mathrm{p} 16.2,6 \mathrm{q} 12$, 6q21, 6q27, 7q35, 10p15.1, 10q22-q23, 10q25-q26, 11q25, 13q12.2, 13q14.3, 13q22.1, 17p13.3 and $17 \mathrm{q} 12$ (Table 2). Most frequently gained clones were mapped to chromosome 1p36, 4p16, 6p12-p21，8q21，8q23-q24， 12q14.3, 16p13.3, 16q24.3，17p11-p12, 19p13.3 and 21q22.3 (Table 3). We explored the possible statistical relationship between copy number alterations and histological and clinical parameters. We found no significant relationship between copy number changes and primary/ metastatic disease, or histological type or histological response. This may be due to the involvement of large number of genomic loci and insufficient sample size.

Homozygous deletions were noted for 32 clones (3.8\%). Recurrent homozygous deletions were noted for 7 clones that are were mapped to 1q25.1 (4 cases), 3p14.1 (4 cases), 13q12.2 (2 cases), 4p15.1 (2 cases), 6q12 (2 cases), $6 \mathrm{q} 12$ (2 cases) and 6q16.3 (2 cases). Figure 2A is showing a homozygous deletion at 3p14.1 in tumor 06 . Loss of $6 \mathrm{q} 12$ region was noted in 35\% of the osteosarcomas. This region was covered with four clones spanning $\sim 4.2 \mathrm{Mb}$. Two tumors (tumor 27 and 345) showed low intensity ratios indicting homozygous deletions in this region, one tumor (tumor 345) showed all 4 deleted clones spanning $\sim 4.2 \mathrm{Mb}$ with RP1-129L7 having the lowest ratio intensity decrease. In another case (tumor 27), two clones (RP1-46B1 and RP1-129L7) showed decreased intensity ratios indicating homozygous deletions. Both these clones spanning approximately $2.6 \mathrm{Mb}$ of $6 \mathrm{q} 12$ region. 
Table 3: Most frequently gained clones.

\begin{tabular}{|c|c|c|c|c|}
\hline Clone & Map Position (Mb) & Cyto Position & Frequency (\%) & Genes \\
\hline RPII-8IF7 & 43.8 & 6p21.1 & 45 & HGNC, MRLPI 4 \\
\hline RPI-I63G9 & 2.6 & Ip36.32 & 43 & PRDM / 6 \\
\hline RPII-79FI3 & 44.6 & $6 p 21.1$ & 37.5 & CDC5L, HSPCB, NFKBIE \\
\hline RPII-90HI7 & 46.5 & $6 p \mid 2.3$ & 37.5 & UCP4 \\
\hline RPII-64LI2 & 0.68 & $16 p \mid 3.3$ & 37.5 & MSLN, SOX8 \\
\hline RPII-637FI6 & $|44.6|$ & $8 q 24.3$ & 35.4 & \\
\hline RP3-447E2I & 46 & 6p21.1 & 35.4 & CLIC5 \\
\hline RPII-7912 & 43.4 & $6 p 21.1$ & 31.2 & EGFL \\
\hline RPII-80F24 & 78.3 & $8 q 21.13$ & 29 & \\
\hline RP4-753D5 & 50.9 & $6 p 12.3$ & 29 & TFAP2B \\
\hline AC005263 & 0.95 & $|9 p| 3.3$ & 29 & AMH, GNRPX, DITIL \\
\hline RPII-I89D22 & 19.56 & $|7 p| \mid .2$ & 29 & TPP3A, SMCR5, DRG2, FLI \\
\hline RPII-89PI9 & 119.5 & $8 q 23.3$ & 27 & \\
\hline RPII-89HI & 77.4 & $8 q 21.13$ & 25 & \\
\hline RPII-88N2 & 43.7 & $21 \mathrm{q} 22.3$ & 25 & SNFILK \\
\hline RPI-283E3 & 1.5 & Ip36.33 & 25 & $C D C 2 L 2, G N B I$ \\
\hline RPII-89P9 & 125.4 & $8 q 24.13$ & 22.9 & MTSSI \\
\hline AL391415 & 43.06 & $6 p 21.2$ & 22.9 & GLOI, DNAH8 \\
\hline RPII-492I23 & 3.64 & $4 p 16.2$ & 22.9 & \\
\hline RPI-I63M9 & 16.2 & $1 p 36.13$ & 22.9 & \\
\hline RPII-383BI5 & 2.89 & $|9 p| 3.3$ & 22.9 & \\
\hline RPII-89K6 & 13.1 & $17 p \mid 2$ & 22.9 & \\
\hline RPII-89KIO & 127.3 & $8 q 24.13$ & 20.8 & NSE2 \\
\hline RPII-90DII & 98.8 & $8 q 22.1$ & 20.8 & \\
\hline RPII-9IEII & 37.4 & $6 p 21.2$ & 20.8 & PIMI \\
\hline RP3-4I7II & 63.04 & $6 p 11.2$ & 20.8 & $B A G 2, R A B 23$ \\
\hline RPII-79O4 & 19.9 & $|7 p| \mid .2$ & 20.8 & ULK2, AKAPIO \\
\hline RPII-46C24 & 101.27 & $16 q 24.3$ & 20.8 & \\
\hline RPII-9IK23 & 67 & $12 q \mid 4.3$ & 20.8 & \\
\hline
\end{tabular}

Amplification is a frequent phenomenon in osteosarcoma Previous studies using CGH have identified several chromosomal amplification sites in osteosarcoma. Because of the limitation of the method, it fails to pinpoint the precise site of amplicon. However, the present study by array CGH has identified 238 clones (28.6\%) with highlevel amplifications. Recurrent amplifications were noted in $\sim 37 \%$ of the total amplified clones (Figure 3 ). These amplified clones were mapped to $1 \mathrm{p} 22,1 \mathrm{p} 31.1$ (ROR1), 1p36.1 (PRDM16), 1q21, 1q23 (TNFF6), 2q24, 3p25, 3q26.1, 4p16.3, 5p14, 5q33, 6p11.2-p21, 7p21, 8q12.1, 8q24.13, 10p21, 10q11.1, 10q22 (KCNMA1), 11q13, $11 \mathrm{q} 23$ (GRIK4), 12q12, 12q13-q15, 12q21-q21.33, 17p11.2-p12, 17q21 (NGFR), 18q22, and 19p13.1 (NFAT). Of these amplified sites, 6p11.2-p21, 8q12.1, $8 \mathrm{q} 24.13,12 \mathrm{q} 12,12 \mathrm{q} 13-\mathrm{q} 15,12 \mathrm{q} 21-\mathrm{q} 21.33,16 \mathrm{p} 13$ and 17 p11.2-p12 were frequent.

Gain of clones from 6p12-p21 regions was noted in 33/48 $(\sim 65 \%)$ cases analyzed. High-level amplification of the clones from same region was noted in $25 \%$ of the cases by array CGH. We found that most of the cases with amplification of 6p12-p21 displayed either increased or slightly varying degree of copy number increase across the 6p12p21 region. The combined log ratios from all the cases defined the boundaries of amplification between RP3329A5 and RP11-79F13. The amplicon spans approximately 9.4 Mb with amplification peak for clone RP1181F7. Further, we used FISH to validate $6 \mathrm{p}$ amplicon on tumor metaphase and interphase cells from cases 274, 364, 426 and 527. Increased copy numbers for clones RP11-91E11, AL391415, RP11-81F7, RP11-79I2, RP11$90 \mathrm{H} 17$ and RP11-79F13 were noted in interphase cells with maximum copy number increase for clone RP11$81 \mathrm{~F} 7$ (Figure 4A). This was consistent with amplification peak for clone RP11-81F7 in the tumors profiled by array CGH (Figure 2B). In addition, we used 2-sample t-test with randomized variance model to define significant clones from 6p12-p21 amplicon. By this method, we identified RP11-79F13 ( $\mathrm{p}=0.00000007), \mathrm{RP} 11-79 \mathrm{I} 2$ ( $\mathrm{p}=$ $0.00000007)$ and RP11-81F7 ( $\mathrm{p}=0.00000007)$ as statistically significant clones.

Most cases with $8 \mathrm{q}$ gain, displayed varying degree of copy number increase predominantly from 8q12.1 (16.9\%), $8 q 21.13(29 \%)$, and 8q24.3 (35\%). High-level amplifica- 



\section{Figure 2}

A representative chromosome profiles showing homozygous deletions (A, E) and high-level amplifications (B- E). The clones showing homozygous deletions from 3pI4.I (RPII-89A I2) and I7qI2 (RPII-7909) in tumor 06 (A, E) and high-level amplifications from 6pl2-p2I in tumor 248(B), 8ql2 in tumors 06 and 34I and 8q23-q24 in tumor 06, (C), I2qI3-qI5 in tumor 48, (D) and I7p I I.2 in tumor 06(E), are shown as log ratios (Y-axis). The clones on each chromosome are arranged (pter to qter) on the basis of UCSC mapping positions.

tions were also noted from 8q12.1 (RP11-550I15 - 6.3\%; Figure 2C), 8q21.13 (RP11-89H1 - 6.3\%), 8q24.3 (RP11$89 \mathrm{~K} 10-6.3 \%)$ and RP11-637F16 (12.5\%). FISH using clone RP11-89K10 ( $\mathrm{p}=0.00049)$ on interphase cells from case 527 confirmed the amplification (10-12 copies) (Figure 4B).
Amplification of $12 \mathrm{q}$ was noted in 14/51 ( 27\%) tumors analyzed by array CGH. Three distinct amplicons - AMP1 (12q12), AMP2 (12q14.1) and AMP3 (12q21.33) were noted across the entire long arm of chromosome 12 (Figure 2D). Of these 14 cases, four of them $(80,123,248$, 341 ) displayed all three amplicons. The AMP1 was noted in 10 cases covering 1.8 Mb region between RP11-91K15 and RP11-90I21 with peak amplification for clone RP11- 


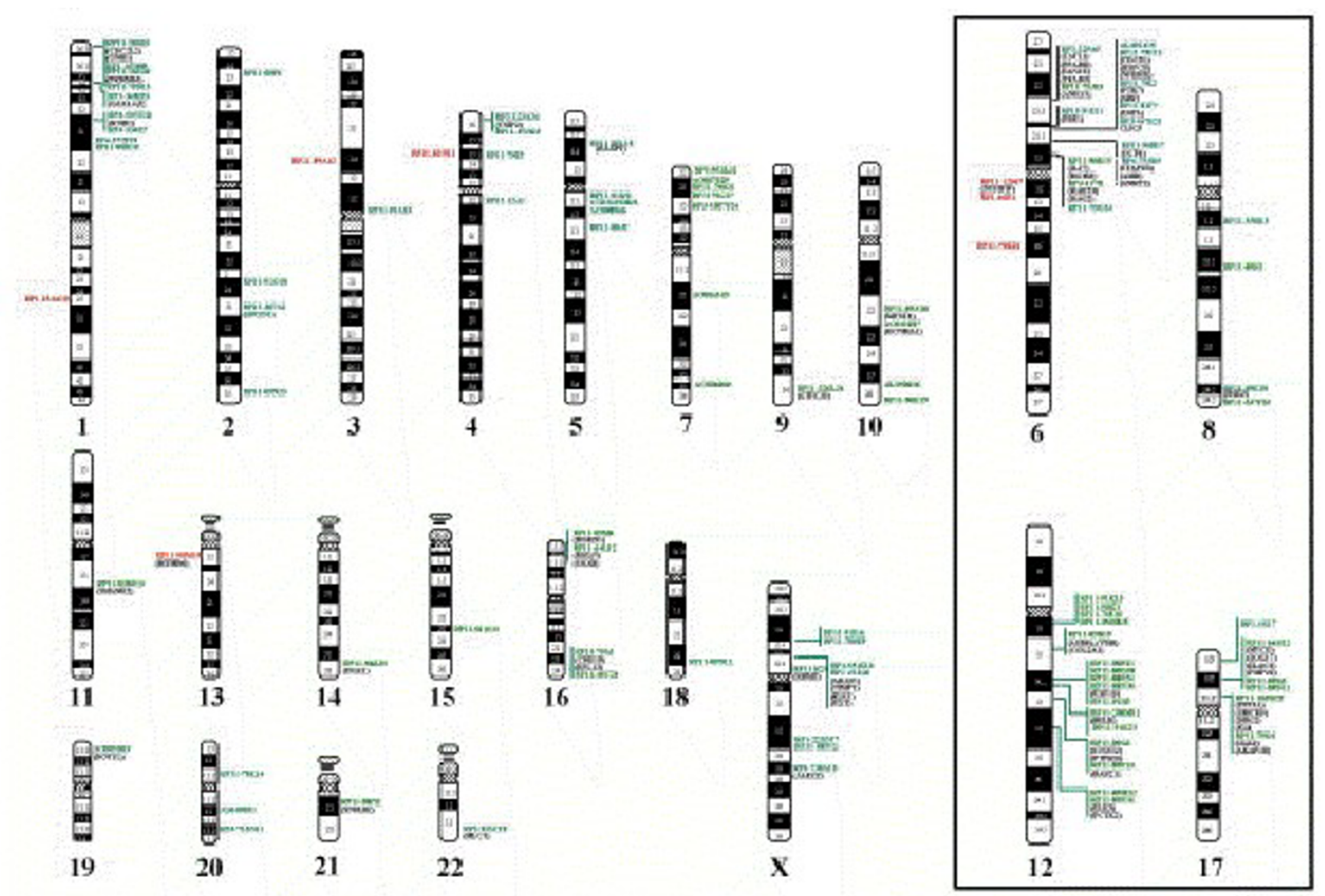

Figure 3

Ideogram showing recurrent homozygous deletions (left) and high-level amplifications (right) identified by array CGH in 48 cases. The gene(s) contained within the BAC clone are shown in parentheses of the respective clones. Gene(s) present in the BAC clones were identified using UCSC browser http://genome.ucsc.edu/cgi-bin/hgGateway?org=human by downloading gene table (refFlat) from human gene assembly, July 2003. The ideograms for chromosomes 6, 8, 12 and 17 are shown separately.

$91 \mathrm{~K} 15$ ( $\mathrm{p}=0.00000004)$. Another amplicon (AMP2) was noted 24.48 Mb distal to AMP1 between RP11-91K23 and RP11-89P15. The AMP3, which was 23.3 Mb distal to AMP2 containing RP11-89F6.

Amplification of $17 \mathrm{p} 11.2$ was noted in $27 \%$ of the cases analyzed by array CGH. The amplicon was composed of three clones RP11-64B12 ( $\mathrm{p}=0.0000014)$, RP11-89K6 ( $\mathrm{p}$ $=0.00000005)$ and RP11-189D22 ( $\mathrm{p}=0.0000001)$ and covering $3.7 \mathrm{Mb}$ region on the short arm of chromosome 17 (Figure 2E). We used these three clones as FISH probes to validate $17 \mathrm{p}$ amplicon in tumors $274,364,425$ and 628 on interphase/ metaphase cells. The distribution of copy number for this amplicon in all the cases ranged from 4-14 copies with peak amplification for clone RP11189D22 (10-14 copies), followed by and RP11-89K6 (810 copies) RP11-64B12 (6-8 copies) (Figure 4C).

\section{Discussion}

This study represents the first application of genome-wide copy number changes by array CGH in osteosarcoma. Recent studies in breast, renal and bladder cancer showed the potential assessment of this technology in detecting high-resolution copy number changes $[9,11,14]$. This approach will augment the identification of cancer causing genes by relating the clone information directly with sequence information from human genome database. In this study, we used array CGH to screen for high-resolution DNA copy number changes and precise identification of amplifications in a panel of 48 osteosarcomas.

Gene amplification is an important genetic mechanism in human cancers, as it clearly associated with tumor progression and has a prognostic significance and has even provided a target for therapeutics $[17,18]$. These amplifi- 

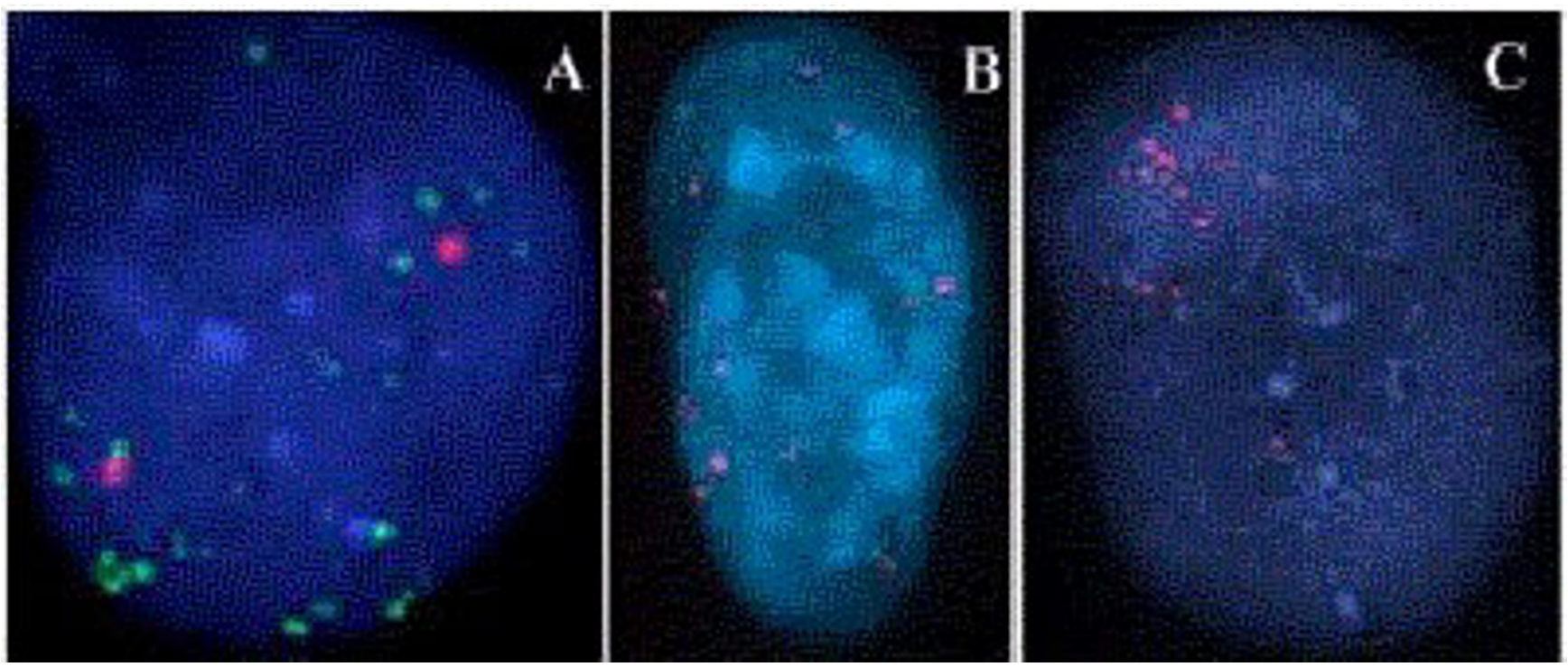

Figure 4

FISH validation of some of the high-level amplifications (6pI2.1, 8q24.3 and I7pII.2) identified by array CGH. Interphase cells hybridized with centromere 6 (red)/RPI I-8IF7 (green) in case 274 (A), RPI I-89K I0 (red) in case 527 (B) and RPI I- I89D22 (red) in case 364 (C). The ploidy of these cases was determined based on the modal chromosome number of the respective cases, e.g. diploid (case 426) triploid (cases 274 and 364), and tetraploid (case 527).

cations are often seen at the cytogenetic level as homozygously staining regions (hsrs) or double minute chromosomes (dms). However, cytogenetic recognition of amplifications doesn't contribute to the mapping and identification of amplified DNA sequences. The advent of CGH points an ever-increasing number of chromosomal amplifications in various tumors. These amplifications contribute to the genomic instability in tumors. We have recently shown that the mutation of $p 53$ significantly correlates with genome-wide DNA instability and seems to represent a major genetic factor contributing to the extremely high levels of genomic instability found in high-grade osteosarcomas [19].

Our analysis have identified frequently amplified clones from 6p11.2-p21, 8q12.1, 8q24.13, 12q12, 12q13-q15, 12q21-q21.33, 16p13 and 17p11.2-p12. Amplification of clones from 6p12-p21 region was noted in $25 \%$ of the cases analyzed. This was consistent with the previously published results by CGH. By array CGH, we refined the $6 \mathrm{p}$ amplicon to $9.4 \mathrm{Mb}$ with amplification peak for clone RP11-81F7. We recently demonstrated the origin of $6 \mathrm{p}$ amplicon as consequence of tandem duplication of clones RP11-81F7 and RP11-79F13 [7]. Based on combined array CGH and FISH analysis suggest CDC5L, HSPCB, and NFKBIE, and HGNC and MRPL14 are the target genes from 6p12-p21 amplicon. Of these genes, CDC5L may be an important gene in cancer because of its role as a posi- tive cell cycle regulator for G2/M transition[20]. Consistent with our analysis, overexpression of HSPCB was shown recently by cDNA microarray studies on osteosarcoma [21]. This protein was shown to play an important role in assemble/disassembly of tubulin by inhibiting tubulin polymerization.

High-level amplifications were also noted from 8q12.1 (RP11-550I15 - 6.3\%), 8q21.13 (RP11-89H1 - 6.3\%), 8q24.3 (RP11-89K10 - 6.3\%) and RP11-637F16 (12.5\%). There were no candidate genes present in clones RP11550I15, RP11-89H1 and RP11-637F16, but clone RP11$89 \mathrm{~K} 10$ contained NSE2 (breast cancer membrane protein $101 \mathrm{kDa}$ gene.

High-level amplification of clones on $12 q$ revealed three distinct sites of amplifications - AMP1 (12q12), AMP2 (12q14.1) and AMP3 (12q21.33). Pervious studies have shown the amplification GLI, CHOP, SAS, HMGI-C, CDK4, HDM2, and PRIM1 from 12q13-q15 region in osteosarcoma $[22,23]$. The present array CGH analysis identified a possible target gene IFNG from AMP2 (RP11$298 \mathrm{M} 11 ; \mathrm{p}=0.0000001)$, which is physically mapped close to the HDM2 oncogene locus[24]. Previous studies demonstrated that T-cell production of IFNG strongly suppresses osteoclastogenesis by interfering with the RANKL-RANK signaling pathway. IFNG induces rapid degradation of the RANK adaptor protein, TRAF6, result- 
ing in strong inhibition of the RANKL-induced activation of the transcription factor NFKB and JNK [25]. The AMP3, which was 23.3 Mb distal to AMP2 containing RP1189F6. Our analysis from AMP3 revealed two interesting candidate genes: transcription factor ELK3 and PCTAIRE protein kinase 2 (PCTK2). ELK3 is a member of the ETSdomain transcription factor family and the protein is activated by signal-induced phosphorylation [26]. The protein encoded by PCTK2 belongs to the $\mathrm{cdc} 2 / \mathrm{cdkx}$ subfamily of the ser/thr family of protein kinases and play an important role in the regulation of the mammalian cell cycle [27]. High-level amplification of three clones from 12 p13 was noted in case 27 and the amplicon span 4.6 $\mathrm{Mb}$ with peak amplification for clone RP11-89D16. No candidate genes contained with in this BAC. Amplification $12 p$ has been reported previously in 9/19 high-grade osteosarcomas by CGH. Recent FISH analysis has identified the amplification of CCND2, ETV6, and KRAS2 from 12 p region [28].

Amplification of $17 \mathrm{p} 11.2$ was noted in $27 \%$ of the cases analyzed by array CGH. Our array CGH analysis has identified three clones with high-level amplifications that spans $\sim 3.7 \mathrm{Mb}$ region on $17 \mathrm{p} 11.2$. Several candidate genes were identified within these clones (TPP3A, SMCR5, DRG2, FL11, MYCD, SOX 17, ELAC2, and PMP22). Recent studies have shown the amplification of some of the genes identified in the present study (PMP22, and TOP3A) from 17p11.2-p12 in high-grade OS by semiquantitative PCR and CDNA microarrays $[29,30]$.

The present array CGH analysis has identified seven recurrent clones exhibiting homozygous deletions from 1q25.1, 3p14.1, 13q12.2, 4p15.1, 6q12, 6q12 and 6q16.3. These chromosomal regions were consistent with previously reported studies by loss of heterozygosity $(\mathrm{LOH})$ and CGH [3-7,31]. The clone, RP11-90M15 (13q12.2) contain possible candidate gene MTMR6, a protein-tyrosine phosphatase gene and shown to be present within a cloned region that encompasses a translocation breakpoint $\mathrm{t}(8 ; 13)$ in an atypical myoproliferative disorder [32]. Homozygous deletions of two clones spanning approximately $2.6 \mathrm{Mb}$ of $6 \mathrm{q} 12$ region containing candidate genes - nuclear fragile X mental retardation protein interacting protein 1 pseudogene (NUFIP1P) and BAI3 gene (brain-specific angiogenesis inhibitor gene), which is to homologous to BAI1 and shown to suppress glioblastoma [33].

\section{Conclusions}

In summary, high resolution array-based CGH revealed large number of chromosomal aberrations previously identified in osteosarcoma by chromosomal CGH and conventional cytogenetic methods. The present study allowed precise identification of smaller DNA copy number alterations, which suggest the presence of specific target genes in osteosarcoma. Although this study suggested several possible target genes from amplified regions from $6 \mathrm{p}, 8 \mathrm{q}, 12 \mathrm{q}$ and $17 \mathrm{p}$, but these genes should be validated by other molecular and immunohistochemical approaches on well-defined large patient samples. Further, interaction or association studies between small genomic losses and gains will facilitate the identification of new genetic pathways in the pathogenesis of osteosarcoma.

\section{Competing interests}

None declared.

\section{Authors contributions}

TKM and KJ have contributed towards the data analysis. $\mathrm{LP}, \mathrm{ML}, \mathrm{RG}$, and CL were assisted in sample collection and clinical information of the patients. X-YL has involved in array CGH experiments and data collection. CPH has involved in extracting the gene information from BAC clones. SS has provided the arrays used in this study. PHR was involved in the planning, and organization of the project.

\section{Acknowledgements}

We thank Prof Rocchi, University of Bari, Italy for providing chromosome 6 centromeric clone and Dr. Richard Simon and Amy Peng for BRB ArrayTools software. This work was supported in part by NIH grant CA88I26 and by grants from the Dunn Foundation and the Kleberg Foundation to C.C.L.

\section{References}

I. Huvos A: Bone Tumors: Diagnosis, Treatment and Prognosis,. Edited by: Huvos A. Philadelphia, WB Saunders; 1991.

2. Provisor AJ, Ettinger LJ, Nachman JB, Krailo MD, Makley JT, Yunis EJ, Huvos AG, Betcher DL, Baum ES, Kisker CT, Miser JS: Treatment of nonmetastatic osteosarcoma of the extremity with preoperative and postoperative chemotherapy: a report from the children's cancer group. J Clin Oncol 1997, 15:76-84.

3. Tarkkanen M, Karhu R, Kallioniemi A, Elomaa I, Kivioja AH, Nevalainen J, Bohling T, Karaharju E, Hyytinen E, Knuutila S: Gains and losses of DNA sequences in osteosarcomas by comparative genome hybridization. Cancer Res 1995, 55: I334-I338.

4. Tarkkanen M, Elomaa I, Blomqvist C, Kivioja AH, KellokumpuLehtinen P, Bohling T, Valle J, Knuutila S: DNA sequence copy number increase at $8 \mathrm{q}$ : a potential new prognostic marker in high-grade osteosarcoma. Int I Cancer 1999, 84: | |4-I2I.

5. Stock C, Kager L, Fink F-M, Gadner H, Ambros PF: Chromosomal regions involved in the pathogenesis of osteosarcoma. Genes Chromosomes Cancer 2000, 28:329-336.

6. Zielenska M, Bayani J, Pandira A, Toledo S, Marrano P, Andrade J, Petrilli A, Thorner P, Sorensen P, Squire JA: Comparative genomic hybridization analysis identifies gains of Ip35-36 and chromosome 19 in osteosarcoma. Cancer Genet Cytogenet 2001, 130:|4-2|.

7. Lau CC, Harris CP, Lu XY, Perlaky L, Gogineni S, Chintagumpala M, Hicks J, Johnson ME, Davino NA, Huvos AG, Meyers PA, Healy JH, Gorlick R, Rao PH: Frequent amplification and rearrangement of chromosomal bands $6 \mathrm{p}|2-\mathrm{p} 2|$ and $17 \mathrm{p} \mid 1.2$ in osteosarcoma. Genes Chromosomes Cancer 2004, 39: II-2I.

8. Pinkel D, Segraves R, Sudar D, Clark S, Poole I, Koebel D, Collins C, Kuo WL, Chen Zhai Y, Dairkee SH, Ljung BM, Gray JW, Albertson D: High resolution analysis of DNA copy number variation using comparative genomic hybridization to microarrays. Nature Genet 1998, 20:207-2II. 
9. Albertson DG, YIstra B, Segraves R, Collins C, Dairkee SH, Kowbel D, Kuo WL, Gray JW, Pinkel D: Quantitative mapping of amplicon structure by array CGH identifies CYP24 as a candidate oncogene. Nat Genet 2000, 25: I44-| 46.

10. Cai WW, Mao JH, Chow CW, Damani S, Balmain A, Bradley A: Genome-wide detection of chromosomal imbalances in tumors using BAC microarrays. Nat Biotechnol 2002, 20:393-6.

11. Wilhelm M, Veltman JA, Olshen AB, Jain AN, Moore DH, Presti JC Jr, Kovacs G, Waldman FM: Array-based comparative genomic hybridization for the differential diagnosis of renal cell cancer. Cancer Res 2002, 62:957-60.

12. Hackett CS, Hodgson JG, Law ME, Fridlyand J, Osoegawa K, de Jong PJ, Nowak NJ, Pinkel D, Albertson DG, Jain A, Jenkins R, Gray JW, Weiss WA: Genome-wide array $\mathbf{C G H}$ analysis of murine neuroblastoma reveals distinct genomic aberrations, which parallel those in human tumors. Cancer Res 2003, 63:5266-73.

13. O'Hagan RC, Brennan CW, Strahs A, Zhang X, Kannan K, Donovan M, Cauwels C, Sharpless NE, Wong WH, Chin L: Array comparative genome hybridization for tumor classification and gene discovery in mouse models of malignant melanoma. Cancer Res 2003, 63:5352-5356.

14. Veltman JA, Fridlyand J, Pejavar S, Olshen AB, Korkola JE, DeVries S, Carroll P, Kuo WL, Pinkel D, Albertson D, Cordon-Cardo C, Jain AN, Waldman FM: Array-based comparative genomic hybridization for genome-wide screening of DNA copy number in bladder tumors. Cancer Res 2003, 63:2872-80.

15. Yang YH, Dudoit S, Luu P, Lin DM, Peng V, Ngai J, Speed TP: Normalization for cDNA microarray data: a robust composite method addressing single and multiple slide systematic variation. Nucleic Acids Res 2002, 30:e I 5.

16. Singh B, Gogineni SK, Sacks PG, Shaha AR, Shah JP, Stoffel A, Rao PH: Molecular cytogenetic characterization of head and neck squamous cell carcinoma and refinement of $3 q$ amplification. Cancer Res 200 I, 6 I:4506-45I3.

17. Lengauer C, Kinzler KW, Vogelstein B: Genetic instabilities in human cancers. Nature 1998, 396:643-649.

18. Schwab M: Oncogene amplification in solid tumors. Review Semin Cancer Biol I999, 9:319-325.

19. Overholtzer M, Rao PH, Favis R, Lu XY, Elowitz MB, Barany F, Ladanyi $M$, Gorlick R, Levine AJ: The presence of $\mathrm{p} 53$ mutations in human osteosarcomas correlates with high levels of genomic instability. Proc Natl Acad Sci U S A 2003, 100: I I547-52.

20. Bernstein HS, Coughlin SR: A mammalian homolog of fission yeast Cdc5 regulates $\mathbf{G} 2$ progression and mitotic entry. J Biol Chem 1998, 273:4666-4671.

21. Wolf M, El-Rifai W, Tarkkanen M, Kononen J, Serra M, Eriksen EF, Elomaa I, Kallioniemi A, Kallioniemi OP, Knuutila S: Novel findings in gene expression detected in human osteosarcoma by cDNA microarray. Cancer Genet Cytogenet 2000, I 23: 1 28-32.

22. Wei G, Lonardo F, Ueda T, Kim T, Huvos AG, Healey JH, Ladanyi M: CDK4 gene amplification in osteosarcoma: reciprocal relationship with INK4A gene alterations and mapping of $12 q \mid 3$ amplicons. Int / Cancer 1999, 80: 199-204.

23. Yotov WV, Hamel H, Rivard GE, Champange MA, Russo PA, Leclecrc JM, Bernstein ML, Levy E: Amplification of DNA Primase I (PRIMI) in human osteosarcoma. Genes Chromosomes Cancer 1999, 26:62-69.

24. Bureau JF, Bihl F, Brahic M, Le Paslier D: The gene coding for interferon-gamma is linked to the $D I 2 S 335$ and $D I 2 S 3 I 3$ microsatellites and to the MDM2 gene. Genomics 1995, 28:109-112.

25. Takayanagi H, Ogasawara K, Hida S, Chiba T, Murata S, Sato K, Takaoka A, Yokochi T, Oda H, Tanaka K, Nakamura K, Taniguchi T: T. cell-mediated regulation of osteoclastogenesis by signaling cross-talk between RANKL and IFN-gamma. Nature 2000, 408:600-605.

26. Lopez M, Oettgen P, Akbarali Y, Dendorfer U, Libermann TA: ERP, a new member of the ets transcription factor/oncoprotein family. cloning, characterization, and differential expression during B-lymphocyte development. Molec Cell Biol 1994, I 4:3292-3309.

27. Meyerson M, Enders GH, Wu C-L, Su L-K, Gorka C, Nelson C, Harlow $E$, Tsai $L-H$ : A family of human cdc2-related protein kinases. EMBO J 1992, I I:2909-2917.

28. Gisselsson D, Palsson E, Hoglund M, Domanski H, Mertens F, Pandis N, Sciot R, Dal Cin P, Bridge JA, Mandahl N: Differentially ampli- fied chromosome 12 sequences in low-and high-grade osteosarcoma. Genes Chromosomes Cancer 2002, 33: I 33-40.

29. van Dartel M, Cornelissen PW, Redeker S, Tarkkanen M, Knuutila S, Hogendoorn PC, Westerveld A, Gomes I, Bras J, Hulsebos T]: Amplification of $17 p \mid 1.2$ approximately $p \mid 2$, including PMP22, TOP3A, and MAPK7, in high-grade osteosarcoma. Cancer Genet Cytogenet 2002, 139:91-96.

30. Squire JA, Pei J, Marrano P, Beheshti B, Bayani J, Lim G, Moldovan L, Zielenska M: High-resolution mapping of amplifications and deletions in pediatric osteosarcoma by use of CGH analysis of cDNA microarrays. Genes Chromosomes Cancer 2003, 38:2I5-25.

31. Yamaguchi T, Toguchida J, Yamamuro T, Kotoura Y, Takada N, Kawaguchi N, Kaneko Y, Nakamura Y, Sasaki MS, Ishizaki K: Allelotype analysis in osteosarcoma: frequent allele loss on 3q, 13q, I 7q, and 18q. Cancer Res 1992, 52:2419-2423.

32. Laporte J, Blondeau F, Buj-Bello A, Tentler D, Kretz C, Dahl N, Mandel J-L: Characterization of the myotubularin dual specificity phosphatase gene family from yeast to human. Hum Molec Genet 1998, 7:1703-17|2

33. Shiratsuchi T, Nishimori H, Ichise H, Nakamura Y, Tokino T: Cloning and characterization of BAI2 and BAI3, novel genes homologous to brain-specific angiogenesis inhibitor I (BAII). Cytogenet Cell Gene 1997, 79:103-108.

\section{Pre-publication history}

The pre-publication history for this paper can be accessed here:

http://www.biomedcentral.com/1471-2407/4/45/prepub
Publish with Biomed Central and every scientist can read your work free of charge

"BioMed Central will be the most significant development for disseminating the results of biomedical research in our lifetime. "

Sir Paul Nurse, Cancer Research UK

Your research papers will be:

- available free of charge to the entire biomedical community

- peer reviewed and published immediately upon acceptance

- cited in PubMed and archived on PubMed Central

- yours - you keep the copyright

Submit your manuscript here:

http://www.biomedcentral.com/info/publishing_adv.asp
BioMedcentral 